Research Article

\title{
Effects of Phaseolus vulgaris Extract on Lipolytic Activity and Differentiation of 3T3-L1 Preadipocytes into Mature Adipocytes: A Strategy to Prevent Obesity
}

\author{
Felipe Castillo, ${ }^{1,2}$ Daniel R. González $\mathbb{D}^{3},{ }^{3,4}$ and Rodrigo Moore-Carrasco $\mathbb{D}^{1,5,6}$ \\ ${ }^{1}$ Departamento de Bioquímica Clínica e Inmunohematología, Facultad de Ciencias de la Salud, Universidad de Talca, \\ Talca, Chile \\ ${ }^{2}$ Laboratorio Clínico, Clínica Alemana de Santiago, Facultad de Medicina Clínica Alemana, Universidad del Desarrollo, \\ Santiago, Chile \\ ${ }^{3}$ Departamento de Ciencias Básicas Biomédicas, Facultad de Ciencias de la Salud, Universidad de Talca, Talca, Chile \\ ${ }^{4}$ Programa de Investigación Interdisciplinario de Excelencia en Quimica y Bio-Organica de Recursos Naturales \\ (PIEI-QUIM-BIO), Universidad de Talca, Talca, Chile \\ ${ }^{5}$ Centro de Estudios en Alimentos Procesados (CEAP), CONICYT-Regional, Gore Maule R09I2001, Chile \\ ${ }^{6}$ Programa de Investigación Asociativa en Cáncer Gástrico (PIA-CG), Universidad de Talca, Talca, Chile
}

Correspondence should be addressed to Rodrigo Moore-Carrasco; rmoorecarrasco@gmail.com

Received 25 January 2019; Accepted 26 February 2019; Published 28 April 2019

Academic Editor: H. K. Biesalski

Copyright ( 2019 Felipe Castillo et al. This is an open access article distributed under the Creative Commons Attribution License, which permits unrestricted use, distribution, and reproduction in any medium, provided the original work is properly cited.

Background. Overweight and obesity are defined as abnormal or excessive fat accumulation that may be harmful for health. A global trend in this area is the search for natural compounds that have a proven beneficial effect and no clinical complications. Phaseolus vulgaris (bean) is a vegetable highly consumed worldwide. One of its effects, the most reported, is weight reduction in overweight individuals. Objective. The objective of this study was to investigate the antiobesity activity of this legume in mature 3T3-L1 adipocytes and in rat white adipose tissue in an ex vivo model. Design. Mature adipocytes 3T3-L1 and rat adipose tissue were treated with bean extracts. We quantified lipolysis in mature 3T3-L1 adipocytes and in rat white adipose tissue in an ex vivo model. Results. In an ex vivo assay with adipose tissue, methanolic and aqueous green bean extracts increased glycerol release to the medium compared to control ( $p<0.05$ and $p<0.001$ respectively). Treatment of 3T3-L1 adipocytes with green bean extracts $(800$ and $1000 \mu \mathrm{g} / \mathrm{mL})$ increased glycerol release significantly $(p<0.0001)$. Extracts at concentrations between 500 and $1000 \mu \mathrm{g} / \mathrm{mL}$ reduced intracellular triglyceride accumulation by $34.4 \%$ and $47.1 \%$ compared to control $(p<0.0001)$. Discussion. Our results propose that bioactive compounds of green beans exert a direct mechanism on adipocytes through lipolysis. Conclusion. We have identified a novel capacity of bean extracts related to lipolytic activity both in vitro and ex vivo, resulting in a powerful lipolytic effect. Moreover, we also found that bean extracts has an antiadipogenic effect during the differentiation of 3T3L1 preadipocytes. These results suggest that bean is a good candidate for the development of functional ingredients that can help reduce the high rates of death from cardiovascular diseases associated with obesity.

\section{Introduction}

Obesity is defined as having a body mass index greater than $30 \mathrm{~kg} / \mathrm{m}^{2}$ and has been recognized as a global epidemic with a myriad of detrimental health effects [1]. For this reason, overweight and obesity are currently a health problem worldwide. It is estimated that the number of overweight and obese individuals has increased from 921 million in 1980 to 2.1 billion in 2013 [2]. Excessive body fat, especially higher visceral adiposity, is associated with an increased risk in the development of numerous adverse health conditions including diabetes and cardiovascular disease $[3,4]$.

This disorder is characterized by enlargement of adipose tissue, which results from the multiplication of fat cells followed by adipogenesis and increased deposition of cytoplasmic triglycerides [5]. It therefore corresponds to an 
increased number and size of adipocytes differentiated from fibroblastic preadipocyte precursors [6].

The process of adipogenesis of 3T3-L1 cells into mature adipocytes involves a highly orchestrated series of events including clonal expansion, growth arrest, and terminal differentiation [7]. Several in vitro models, particularly murine 3T3-L1 preadipocytes which can be differentiated into mature adipocytes, have improved our understanding of the mechanisms involved in obesity $[8,9]$. Inhibition of adipogenesis and restoration of adipocyte function are considered to be important antiobesity mechanisms.

In the literature, it has been reported a large number of natural products that are capable of inhibiting adipogenesis, to induce apoptosis of adipocytes and/or to stimulate lipolysis. This would have great potential for treating and preventing obesity $[10,11]$.

Among the main foods that have these characteristics and are consumed by people worldwide are legumes. Within the group of leguminous plants that have edible seeds, beans or common beans (Phaseolus vulgaris) correspond to one of the most consumed. It is currently distributed in the five continents and is an essential component of the diet, especially in Central and South America where it is consumed as dry grain and green beans [12].

Previous studies have shown the nutritional and beneficial effects on metabolism of beans consumption, showing a wide range of phytochemicals, many of them with antioxidant capacity in vitro [13]. It has been shown that intake of beans exerts inhibitory effects on appetite as well as beneficial effects on carbohydrate metabolism both in rodents and in humans $[14,15]$. Also, those common beans are nutritional ingredients that reduce the risk of cardiovascular diseases associated with platelet hyperreactivity [16].

This effect on carbohydrate metabolism is produced by a group of inhibitors of the activity of enzymes responsible for degradation of complex carbohydrates from the diet, preventing their absorption [17]. Gupta et al. purified a potent inhibitor present in Phaseolus vulgaris with the ability to inhibit the activity of human salivary alpha-amylase [18]. This effect on carbohydrate metabolism has been assumed to be related to weight loss in humans and animals. However, this effect alone could not explain all the observed effects observed in vivo.

The aim of the present study was to investigate the antiobesity activity of this legume by quantifying lipolysis in mature 3T3-L1 adipocytes and in rat white adipose tissue in an ex vivo model.

\section{Materials and Methods}

2.1. Bean Samples. To evaluate the ex vivo lipolytic effect, we used the variety of Phaseolus vulgaris (bean) at different growing seasons (green beans (green pods and grain) and fresh beans (shelled bean)) for study. For the in vitro lipolytic and antiadipogenic effect, we only used green beans. The samples were selected and obtained from the Regional Supply Center (CREA), Talca, Chile.
2.2. Aqueous Extracts. Selected beans were washed and cut into small pieces. Using a blender were crushed and then methanol was added (Sigma-Aldrich, St. Louis MO, USA) in a ratio $80: 20$ distilled water/methanol. Then, the mixture was sonicated (Transsonic 700/H, Elma-Hans Schmidbauer, Germany) for 15 minutes, and then filtered with filter paper twice. The filtrate was subjected to rotary evaporation (RE 111-B461, BÜCHI Labortechnik AG, The Netherlands) for the full elimination of methanol. The resulting liquid was lyophilized (Freezone 6 Labconco, USA) and then was weighed and stored until use at $-70^{\circ} \mathrm{C}$ (Ultra Low, Sanyo Electric Co., Ltd., Japan).

2.3. Animals. The samples used were obtained from dorsal white adipose tissue, from male Sprague-Dawley rats (obtained from the animal facility of Universidad de Talca) weighing between 200 and $300 \mathrm{~g}$. The animals were maintained at $22 \pm 2^{\circ} \mathrm{C}$ with a regular light-dark cycle (12 hour light and 12 hour dark) and had free access to food and water. All animal manipulations were made in accordance with the Bioethical Committee of the National Commission of Science and Technology, CONICYT, Chile, and approved to the Bioethical Committee of the University of Talca. For adipose tissue extractions, the abdominal cavity of each rat was opened, the intestines were removed, and the area beside the vertebral behind the kidneys spine was exposed. Then, adipose tissue was removed and washed three times with cold PBS. Subsequently, the extracted tissue was divided into segments of $100-110 \mathrm{mg}$.

2.4. Anesthesia and Sacrifice. Animals were weighed and anesthetized with a ketamine $(50 \mathrm{mg} / \mathrm{kg}$ ) (anesthetic)/xylazine $(5 \mathrm{mg} / \mathrm{kg}) \quad$ (muscle relaxant)/acetopromazine $(1 \mathrm{mg} / \mathrm{kg})$ (sedative). Death was caused by blood collection after the opening of the peritoneal cavity and secured by diaphragm rupture. The surgical material used was sterile.

2.5. Continuous Gassing System. We used a custom-made gas distributor of carbogen from a source of carbogen (95\% $\mathrm{O}_{2}-5 \% \mathrm{CO}_{2}$ ) to a series of glass vials which contained $4 \mathrm{~mL}$ Krebs-HEPES buffer (pH 7.4 (reaction medium)) and white adipose tissue. Glass vials were immersed in a temperaturecontrolled bath under constant stirring at $37^{\circ} \mathrm{C}$ when gassing with carbogen.

2.6. Ex Vivo Lipolysis in WAT. Each glass vial was filled with $4 \mathrm{ml}$ of buffer containing $1 \mathrm{mg} / \mathrm{ml}$ green bean extract and $1 \mu \mathrm{M}$ epinephrine (Sigma-Aldrich) as a positive control of adipose tissue lipolysis, via their action on the $\beta 2$-adrenergic receptor. Vials were incubated for 15 minutes at $37^{\circ} \mathrm{C}$. After 15 minutes of preincubation, the WAT pieces were added into the vials and were incubated for 1 hour at $37^{\circ} \mathrm{C}$ under constant stirring. After incubation, the continuous gassing system was stopped and the vials were placed on the ice to terminate the reaction. The adipose tissue was removed from the liquid, and the medium was stored at $-80^{\circ} \mathrm{C}$ until measurement of glycerol. 
2.7. Cell Culture and Adipocyte Differentiation. 3T3-L1 mouse preadipocyte cell line was obtained from American Type Culture Collection (ATCC, Manassas, VA, USA) and cultured in Dulbecco's modified Eagle medium (DMEM) high glucose (HyClone Laboratories, USA, Cat No. SH30243.01) containing 10\% fetal bovine serum (HyClone Laboratories, USA, Cat No. SH30910.03) and $100 \mathrm{U} / \mathrm{mL}$ penicillin-streptomycin (Biological Industries, USA, No. $03-033-1 \mathrm{~B}$ ) at $37^{\circ} \mathrm{C}$ in a humidified $5 \% \mathrm{CO}_{2}$ incubator. Cells were seeded in 12-well plates at a density of $3 \times 10^{5}$ cells/well or in 24-well plates at a density of $6 \times 10^{4}$ cells/well. Cells were grown to confluence $90 \%$ in DMEM/high glucose containing $10 \% \mathrm{FBS}$ at $37^{\circ} \mathrm{C}$ and $5 \% \mathrm{CO}_{2}$ in humidified air. Forty-eight hours after visual confluence (day 0), cell differentiation was induced by culturing in adipogénesisinducing medium (DMEM/high glucose containing 10\% FBS, $1 \mu \mathrm{M}$ dexamethasone (Sigma, USA, Prod. Nos. D4902), $0.5 \mathrm{mM}$ IBMX (Sigma, USA, Prod. Nos. I5879), and $10 \mu \mathrm{g} / \mathrm{mL}$ insulin (Sigma, USA, Prod. Nos. I927)) for two days. On Day 2, cells were then cultured in adipogenesis maturation medium (DMEM/high glucose containing 10\% FBS and $10 \mu \mathrm{g} / \mathrm{mL}$ insulin) for two days. Subsequently the cells were cultured in maintenance medium (DMEM/high glucose $10 \%$ FBS) for six days, with refreshment every two days. The effect on adipogenesis was assessed by adding increasing concentrations of the plant extract $(500,800$, and $1000 \mu \mathrm{g} / \mathrm{mL}$ ) to the culture media during all processes of differentiation. Cells cultured only in maintenance medium were used as a control in all assays.

2.8. Cytotoxicity Assay. 3T3-L1 preadipocytes were seeded in 96-well plates $\left(2 \times 10^{4}\right.$ cells/well $)$ and allowed to adhere overnight in DMEM/high glucose. After discarding the medium, a culture medium containing green bean extracts (20 to $1000 \mu \mathrm{g} / \mathrm{mL}$ green beans) was added to each well and the cells were incubated for 24 to $48 \mathrm{~h}$; untreated cells were used as controls. After completion of the time period, the cells were washed with PBS carefully and the medium was replaced with a medium containing MTT (3-[4,5-dimethylthiazol-2yl]-2,5-diphenyltetrazolium bromide) $5 \mathrm{mg} / \mathrm{ml}$ (10 $\mu \mathrm{L} /$ well $)$ in DMEM and incubated at $37^{\circ} \mathrm{C}$ for an additional $4 \mathrm{~h}$. Finally, the medium was removed, and the formazan produced was dissolved in $100 \mu \mathrm{L} \mathrm{HCl} 0.1 \mathrm{~N}$ solution in isopropanol for 30 minutes in darkness. Absorbance of solution was measured at $570 \mathrm{~nm}$ using a microplate reader (Multiskan Go, Thermo Scientific). Cell proliferation (\%) was calculated by the following equation: (absorbance of the sample/mean absorbance of the control) $\times 100$.

2.9. In Vitro Lipolysis in 3T3-L1 Cells. The effect of the green bean extracts on lipolysis was quantified by adding increasing concentrations $(20,40,60,500,800$, and $1000 \mu \mathrm{g} /$ $\mathrm{ml}$ ) of green bean extract to differentiated adipocytes for $48 \mathrm{~h}$. Isoproterenol (Sigma, USA, Lot SLBK3425V), a known stimulator of adipolysis, was used as a positive control in all assays. Glycerol release was quantified using a kit (EnzyChrom $^{\mathrm{TM}}$ Glycerol Assay Kit, BioAssay Systems, USA).
2.10. Oil Red O Staining. 3T3-L1 preadipocytes were differentiated in 24-well plates and treated with the extracts as described previously. After differentiation, cells were washed twice with PBS and fixed with $4 \%$ (v/v) paraformaldehyde for $1 \mathrm{~h}$ at room temperature. Thereafter, cells were washed one time with PBS and one more time with isopropanol 60\% $(\mathrm{v} / \mathrm{v})$ and were allowed to dry. Then, cells were stained with filtered Oil Red O solution 0.5\% (v/v) (60\% isopropanol and $40 \%$ water) for $1 \mathrm{~h}$. After staining, the Oil Red O staining solution was removed, and the plates were rinsed with distilled water thrice and dried. The stained lipid droplets were viewed at $20 x$ and $40 x$ magnification on a microscope and were photographed.

2.11. Intracellular Lipids Accumulation. The stained oil droplets were solubilized by incubating with isopropanol $100 \%(\mathrm{v} / \mathrm{v})$ for $15 \mathrm{~min}$ and absorbance, an indication of lipid accumulation, was quantified at $492 \mathrm{~nm}$ on a plate reader (Multiskan Go, Thermo Scientific).

2.12. Triglyceride Assay. To analyze the content of cellular triglycerides, after differentiation and treatment with extracts in 24-well plates, 3T3-L1 adipocytes were washed with PBS, scraped into $200 \mu \mathrm{l} \mathrm{PBS}$, and sonicated for $3 \mathrm{~min}$. Thereafter, the suspension was centrifuged to $3500 \mathrm{rpm}$ for $10 \mathrm{~min}$. Intracellular triglycerides were quantified using a triglyceride kit according to the manufacturer's instructions (Triglycerides Liquicolor, Human, Germany). The results were expressed as \% of triglycerides compared to control.

2.13. Statistical Analysis. Data are expressed as mean\pm standard error of the mean (SEM). Differences between groups were analyzed by one-way analysis of variance (ANOVA) using Tukey's post hoc test using SPSS version 17.0 (SPSS, Inc., Chicago, Illinois) and GraphPad Prism 7. A value of $p<0.05$ was considered significant.

\section{Results}

3.1. Effects of Bean Extracts on Lipolysis Ex Vivo. To assess the ability of bean extracts to stimulate lipolysis under physiological conditions, a series of ex vivo assays with rat adipose tissue was performed. The dorsal adipose tissue was removed from SD rats; this was washed with saline and incubated in the presence of different extracts at $1 \mathrm{mg} / \mathrm{ml}$ concentration. Lipolysis was assessed by measuring glycerol released to the medium as a marker for degradation of triglycerides.

Figure 1 shows the results obtained for aqueous and methanolic extracts of green beans, where it is appreciated that both extracts have a significant effect of inducing lipolysis ( $p<0.05$ compared to negative control). With respect to the controls (positive and negative), they are statistically significant as well.

3.2. Effects of Bean Extracts on Cytotoxicity. Before assaying the extracts with the cell line, it was necessary to carry out a cytotoxicity test to obtain the concentration at which the 


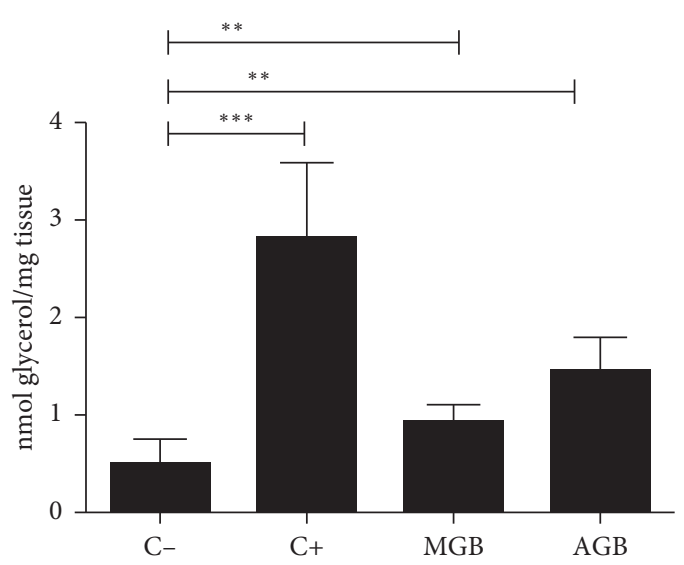

Figure 1: Effect of methanol extracts of green beans (MGB) and aqueous green beans (AGB) on lipolysis ex vivo. $\mathrm{C}-$ : negative control; C+: positive control; $n=5$. ${ }^{* *} p<0.05$; ${ }^{* * *} p<0.001$.

extract begins to be cytotoxic, in order to rule out that the extract does not influence cell viability. The level of viability that was required should be $>90 \%$. A cell viability curve was performed in a range of 20 to $1000 \mu \mathrm{g} / \mathrm{mL}$ of green bean concentrations. To investigate whether $P$. vulgaris exhibits cytotoxicity, mitochondrial dehydrogenase was assessed using the MTT assay. None of the concentrations of green bean extracts used during the study decreased mitochondrial dehydrogenase activity, as shown in Figure 2.

3.3. Effects of Bean Extracts on Lipolysis In Vitro. Treatment of 3T3-L1 adipocytes with the extracts and isoproterenol, a nonspecific adrenergic agonist, increased the amount of glycerol released (Figure 3) although statistical significance was noted for green bean extract concentrations between 800 and $1000 \mu \mathrm{g} / \mathrm{ml}$ induced lipolysis, with maximal stimulation observed from $800 \mu \mathrm{g} / \mathrm{ml}(p<0.001)$.

\subsection{Effects of Bean Extract on Lipid Droplet Formation in 3T3-} L1 Adipocytes. The differentiation of preadipocytes to mature adipocytes is associated with the increase in the number of cells stained with Oil Red $\mathrm{O}$ and lipid accumulation. The microscopic observation of the Oil Red O stain shows an intracellular reduction in the number and size of lipid droplets accumulated in the cells treated with GB at the three concentrations compared to the control cells or those that were not treated and that reached complete differentiation (Figure 4).

Next, the accumulation of fat after cell differentiation of treated and untreated cells with green bean was quantified spectrophotometrically. The different concentrations of green bean extract exhibited similar effects on lipid accumulation, as shown in Figure 5. Concentrations of 500 to $1000 \mu \mathrm{g} / \mathrm{mL}$ reduced intracellular lipid accumulation by $20 \%$ compared to control $(p<0.001)$.

3.5. Effects of Extracts on Intracellular Triglyceride (TG) Content in 3T3-L1 Adipocytes. Figure 6 shows that all

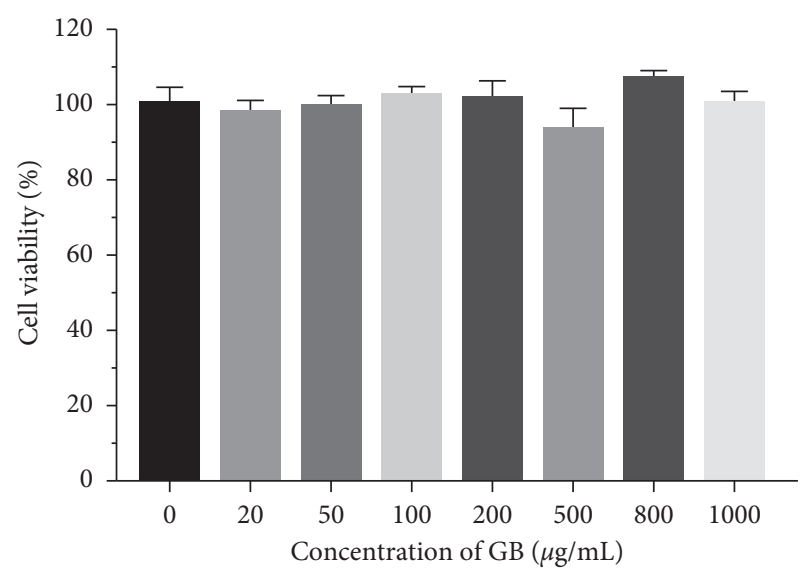

FIGURE 2: Effect of green bean extract on mitochondrial dehydrogenase activity. 3T3-L1 preadipocytes were incubated for 48 hours with concentrations of 20 to $1000 \mu \mathrm{g} / \mathrm{mL}$ of green beans (GB). MTT values were calculated as a percentage respect to untreated cells. $n=5$ in each assay.

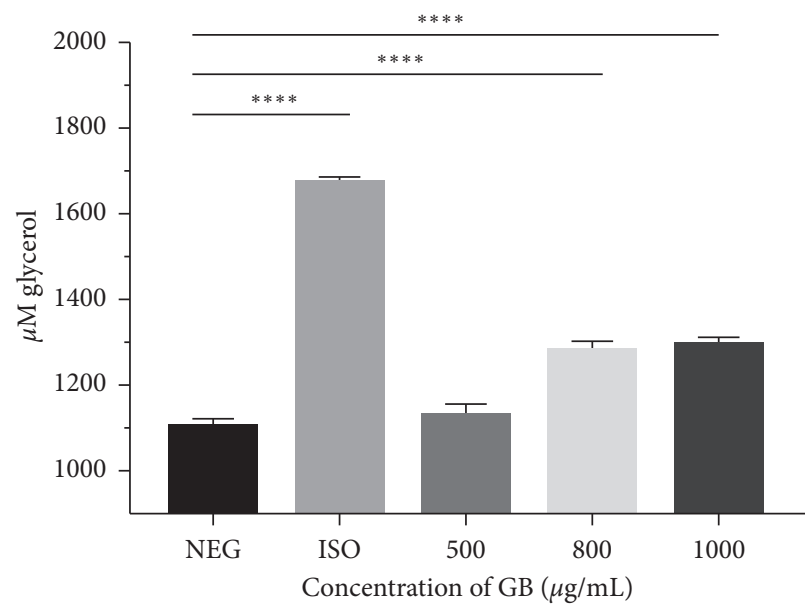

FIGURE 3: Lipolytic activity of green bean extract on 3T3-L1 mature adipocytes. NEG: negative control; ISO: positive control of $10 \mu \mathrm{g} / \mathrm{mL}$ isoproterenol and green bean extract (GB); $n=8$. ${ }^{* * * *} p<0.0001$.

concentrations of the green bean extract (500 to $1000 \mu \mathrm{g} / \mathrm{mL}$ ) decreased intracellular triglyceride accumulation compared to the untreated control. Green bean extracts reduced triglyceride accumulation by $34.4 \%$ at $500 \mu \mathrm{g} / \mathrm{mL}$ and $47.1 \%$ at 800 and $1000 \mu \mathrm{g} / \mathrm{mL}(p<0.0001)$.

\section{Discussion}

The high mortality presented by CVD is directly related to the high prevalence in the population of modifiable cardiovascular risk factors such as diet [19]. It is therefore necessary to create a "new nutrition" that relates the healthy diet as a key factor in health and quality of life. It is therefore essential to promote a healthy lifestyle and diet in the population and to encourage the consumption of a Mediterranean diet, which is rich in fruits and vegetables. 

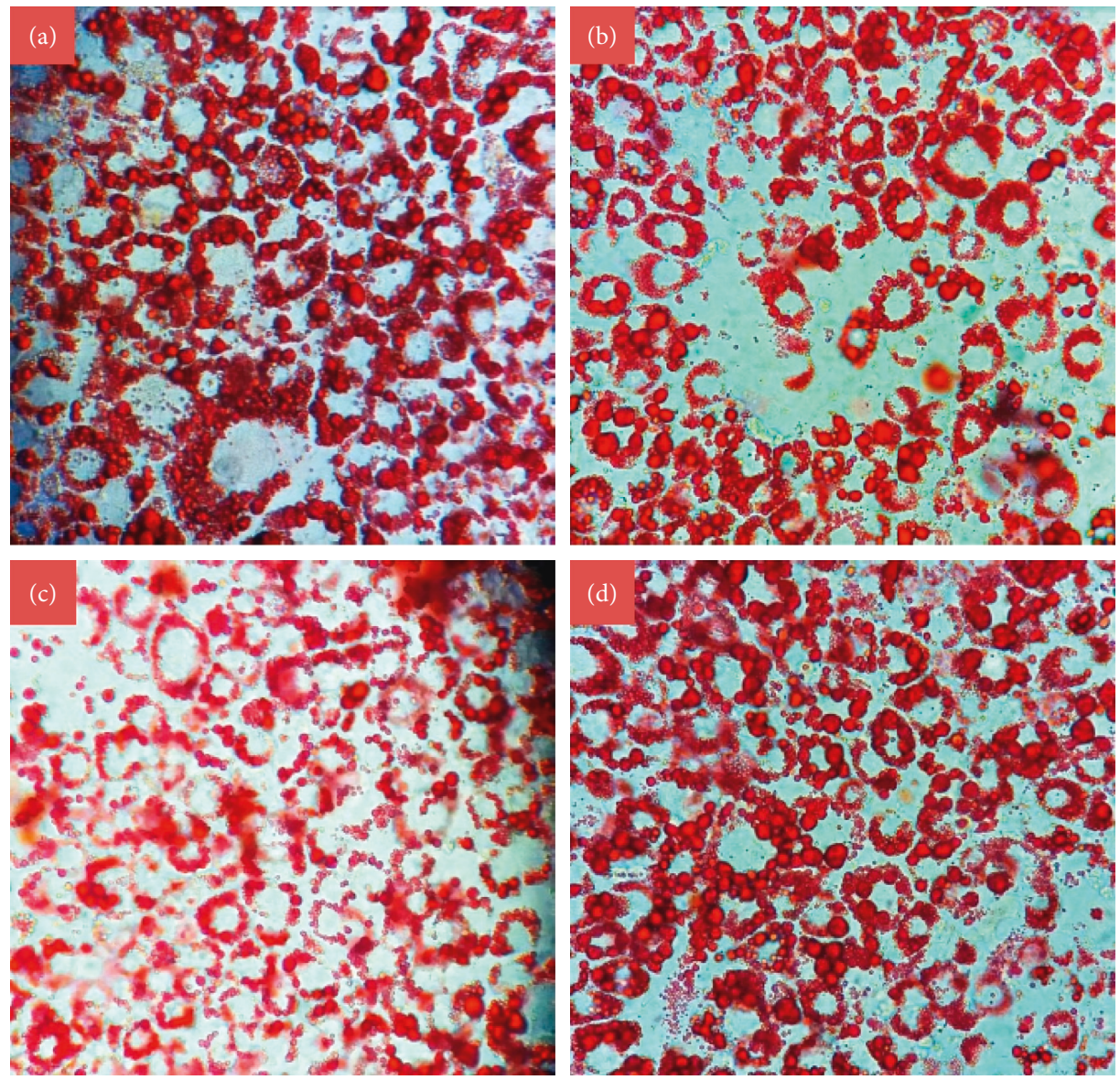

FIGURE 4: Staining with Oil Red O. Effect of green bean extract on adipogenesis of 3T3-L1 cells. (a) Mature adipocytes stained on Day 8 after induction of differentiation. Mature adipocytes stained were subjected to differentiation with $500 \mu \mathrm{g} / \mathrm{mL}$ (b), $800 \mu \mathrm{g} / \mathrm{mL}$ (c), and $1000 \mu \mathrm{g} / \mathrm{mL}$ (d) of GB, on Day 8 after induction of differentiation. 40x objective photographs.

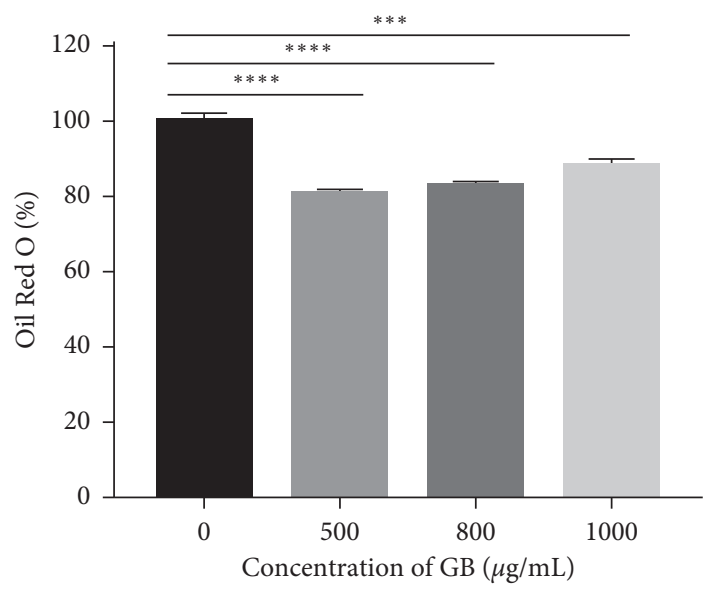

Figure 5: Green bean extract inhibits the intracellular accumulation of lipids in 3T3-L1 cells. The values of total lipid accumulation relative to spectrophotometry of the staining $(492 \mathrm{~nm})$ were calculated as a percentage relative to the untreated cells. $n=5$. ${ }^{* * *} p=0.0006 ;{ }^{* * * *} p<0.0001$.

Therefore, plant foods such as fruits and vegetables, in addition to the nutritional contribution, may be used as healthy beneficial elements such as functional foods [20] and

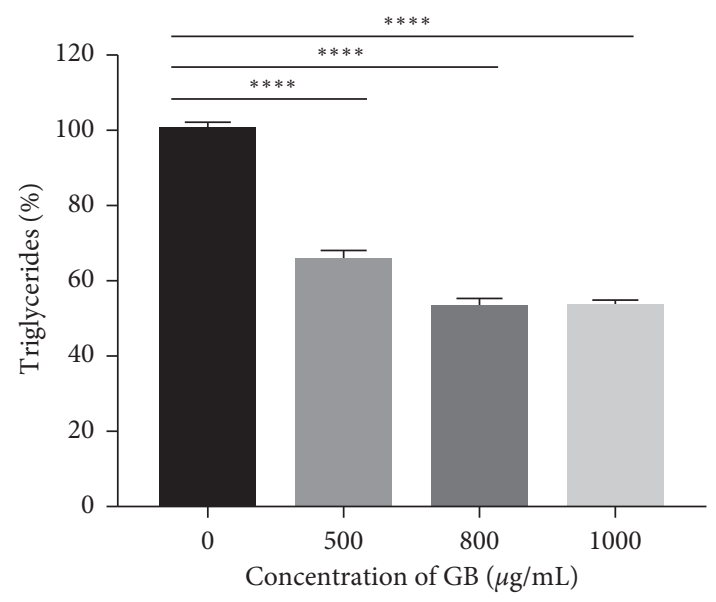

FIgURE 6: Green bean extract inhibits the accumulation of triglycerides in $3 \mathrm{~T} 3$-L1 cells. The reduction of the total triglycerides per well was calculated as a percentage relative to the untreated cells. $n=8$. ${ }^{* * * *} p<0.0001$.

bioactive phytochemicals. Another important risk factor in the development of CVD and ischemic events is obesity [21]. Until recently, it was thought that adipose tissue was 
exclusively involved in energy reserve, but now, there is enough evidence showing that adipose cells exert autocrine, paracrine, and endocrine effects [22]. The excessive accumulation of fat in different parts of the body is a risk factor for the secretion of inflammatory mediators and hormones that regulate metabolism and intake, including cytokines such as TNF-alpha and IL-2, key inflammatory mediators in endothelial dysfunction, the first event in the development of CVD [23]. Our aim was to evaluate the ability of bean extracts to induce direct lipolysis in adipose tissue. This effect has not been reported for these beans, and the results clearly show that the bean extracts significantly stimulated lipolysis in rat adipose tissue ex vivo. Along with this, we have determined that the compound or compounds responsible for the observed effect is modulated by the state of maturation of the grain, being green bean extract that presented a stronger effect than shelled bean extract. Moreover, it is probably that the responsible molecule for this activity has a higher partition in the aqueous solvent since greater effect can be observed in the aqueous than in the methanolic extracts. There has been a recent study which evaluated the ability of extracts of "black adzuki bean" on adipocytes in culture and found that this extract has antiadipogenic effects [24]. Another recent publication by Stefanon et al. showed that extracts of Rosmarinus officinalis can modulate adipocyte differentiation and metabolism, modulating triglyceride accumulation [25].

Most of the studies looking for effects at the level of adipose tissue using extracts are based on diets with these natural products. With the use of an in vitro model of adipocyte cells, we have focused on testing the effect directly on preadipocytes and mature adipocytes in cell culture conditions and therefore assessed their lipolytic and inhibitory effects on adipogenesis.

In relation to obesity and in search for new natural strategies for its treatment, our objective was to evaluate the ability of green bean extract to induce lipolysis directly on mature 3T3-L1 adipocytes in vitro, an effect that has not been reported by this type of bean in a cell culture model. After incubation for 48 hours with the extract, our results indicate that, at concentrations of 20,40 and $60 \mu \mathrm{g} / \mathrm{ml}$, there is no increase in glycerol in the extracellular medium; therefore, direct stimulation of lipolysis was not reported. With these results, we discarded the use of low concentrations due to its limited effect; however, in previous studies with green bean, this extract at a concentration of $1 \mathrm{mg} / \mathrm{mL}$ presents direct lipolytic activity on rat white adipose tissue, an ex vivo model, in comparison with aqueous and methanolic garnet bean extracts that did not have significant results on direct lipolysis of the same model.

Although in the ex vivo model, we used this concentration of extract, incubated for 1 hour on adipose tissue, we decided to submit 3T3-L1 cells to concentrations of $1000 \mu \mathrm{g} / \mathrm{mL}$ in the cell viability experiment. Our results indicate that higher concentrations of the extract do not cause negative effects on the cells because after incubation, they maintain viability greater than $90 \%$. With this, we decided to carry out the same in vitro lipolysis experiment with green bean extract but with concentrations of 500, 800, and $1000 \mu \mathrm{g} /$
$\mathrm{mL}$, respectively. The results indicate that, at concentrations of 800 and $1000 \mu \mathrm{g} / \mathrm{mL}$, there is direct stimulation of lipolysis. In addition, it is shown that there is a tendency that the release of glycerol is increased as the concentration increases, evidencing that these types of bean have lipolytic activity both in vitro and ex vivo. In the literature, this phenomenon has been related to the high polyphenol content of Phaseolus vulgaris $(0.4 \%)$, where the main polyphenolic compounds correspond to tannins, phenolic acids, and flavonoids. Among the vegetables with the highest content of polyphenols are pigmented beans such as the red bean ( $P$. vulgaris) and the black bean (Vigna mungo), noting that these bioactive compounds have important antioxidant properties [26, 27].

In most studies where there is an implication effect of beans, the experiments are based on the intake of $P$. vulgaris, with a reduction of body mass, satiety, and lipids in obese animals [28]. A series of inhibitory proteins of hydrolases present in beans are active against proteases, amylases, lipases, and glycosidases. It has been shown that the administration of an inhibitor derived from the black bean slows the digestion of starch with the reduction of serum glucose and insulin concentrations, in addition to increasing the metabolism of nonesterified fatty acids from adipose tissue in rats. The extract of $P$. vulgaris inhibits the activity of $\alpha$-amylase, preventing the enzyme from acting on starch, and therefore, the postprandial hyperglycemia is reduced, which leads to less fat storage in adipocytes [15, 29]. Another compound found in beans is lectins, specifically phytohaemagglutinin, a glycoprotein associated with the reduction of insulin levels and lipid accumulation [30]. Therefore, one way in which compounds induce low body mass is indirectly through satiety and causing a low starch digestion. Our results propose that bioactive compounds of green beans also exert a direct mechanism on adipocytes through lipolysis.

Related to the aforementioned, in vivo studies have reported that the daily use of an oral nutritional supplement with $445 \mathrm{mg}$ of an extract of $P$. vulgaris ("Phase2TM"), derived from white bean, during 30 days in overweight volunteers, caused a significant decrease in body mass and decrease in fat mass. Therefore, the inclusion of $P$. vulgaris in the diet and/or in vitro studies on adipocytes is an interesting antiobesity target [31].

There is a series of natural compounds in fruits and vegetables with lipolytic effects, but those associated with beans are few. However, in 2012, a study evaluated the effect of "black adzuki" (Vigna angularis), a legume grown in the east, as a potential antiobesity product. In this study, it is indicated that this extract exerts a significant reduction in the accumulation of liver lipids in in vivo studies. On the contrary, in a in vitro study, incubation of human adipocytes with the extract $(250,500$, and $1000 \mu \mathrm{g} / \mathrm{ml}$ in sterile water) produced a significant decrease in triglyceride accumulation without affecting the cell viability and the reduction of inflammatory response [32]. Although in this work intracellular triglycerides were not quantified in mature adipocytes submitted to the GB extract, glycerol levels were measured to determine lipolysis. It is expected that there may also be an intracellular fat reduction; our results are 
comparable since they used concentrations higher than $0.5 \mathrm{mg} / \mathrm{ml}$.

It has recently been published that black adzuki bean has antiadipogenic effects in adipocyte culture. In this study, it was observed that the extract is able to inhibit cell proliferation and suppress adipogenesis in early phases of differentiation associated to a lower expression of $\mathrm{C} / \mathrm{EBP} \beta$. In addition, it causes a reduction of triglycerides depending on dose and time; there was also lower expression of GLUT4, FABP4, LPL, and adiponectin. Compared to the control group, the groups treated with bean extract exhibit a higher expression of lipolytic genes such as ATGL and HSL [24]. Regarding our results and the effects on adipogenesis of 3T3L1 preadipocytes until mature adipocytes, they indicate that there is a reduction in lipid accumulation at the end of the test, as well as triglycerides, suggesting that the green bean exerts an anti-adipogenic effect. The concentrations used are also high and range from $500 \mu \mathrm{g} / \mathrm{mL}$ to $4 \mathrm{mg} / \mathrm{mL}$ and from 0.5 to $2.5 \mathrm{mg} / \mathrm{mL}$; the extract of the adzuki bean is not toxic as well as the green bean, which suggests that beans in general can be used at these concentrations on average, when used in adipocyte cell cultures. Unlike the study indicated above, we cannot determine whether the green bean exerts inhibition of early or late adipogenesis because we did not quantify the expression of genes such as PPAR $\gamma$ and C/EBP $\alpha$ and $\beta$. It should be noted that the increase in HSL expression, lipolysis itself, also indicates the possible way in which the green bean acts on mature adipocytes; therefore, it may also be important to measure the expression of this gene in adipocytes.

As mentioned at the beginning, beans in general and especially the pigmented ones contain several polyphenols such as proanthocyanidins, quercetin, and genistein. These antioxidants have been shown to inhibit proliferation and adipogenesis. Other studies suggest that genistein promotes lipolysis and inhibits adipogenesis in cell culture, in addition to the fat content of preadipocytes in differentiation [33]. This suggests that the polyphenolic compounds of the green bean extract are those that exert the lipolytic and antiadipogenic effects shown in the results; therefore, a projection is to evaluate and quantify the content of antioxidants and polyphenols of the extract itself.

Another compound with antioxidant properties that has been described in a series of vegetables, fruits, and tea is myricetin, a flavonoid. This flavone has been described as anticarcinogenic, anti-inflammatory, and antihyperlipidemic; however, it was recently described that myricetin suppresses the differentiation of 3T3-L1 preadipocytes by reducing the expression of $\mathrm{C} / \mathrm{EBP} \alpha$ and $\operatorname{PPAR} \gamma$ together stimulates lipolysis in adipocytes by reducing the expression of perilipin A, classifying it as an antiobesity compound [34]. The latter also suggests that green beans may not only induce lipolysis by increasing the expression of HSL but also by stimulation of pathways related to perilipin A; it can also have an effect on cell differentiation by inhibiting the expression of genes $\mathrm{C} /$ $\operatorname{EBP} \alpha$ and $\operatorname{PPAR} \gamma$.

The lipolytic and antiadipogenic effects arising from bean extracts represent an interesting food strategy in the treatment of cardiovascular diseases because it directly affects one of the most important risk factors for the development of CVD and obesity. This study is a starting point for identifying and studying the active principles and effects in vivo.

\section{Conclusion}

Here, we showed that green bean extract has a direct lipolytic effect on mature adipocytes 3T3-L1, with the consequent release of glycerol, at concentrations of the extract that do not affect cell viability. The use of the green bean extract from the beginning of preadipocyte differentiation shows antiadipogenic effects; therefore it reduces lipid accumulation at the end of the process.

\section{Abbreviations}

IBMX: 3-Isobutyl-1-methylxanthine

MTT: 3-(4,5-Dimethylthiazol-2-yl)-2,5diphenyltetrazolium bromide

CVD: Cardiovascular diseases

TNF: Tumor necrosis factor

GB: Green bean

C/EBP: CCAAT-enhancer-binding proteins

GLUT4: Glucose transporter type 4

FABP4: Fatty acid-binding protein 4

LPL: Lipoprotein lipase

ATGL: Adipose triglyceride lipase

HSL: Hormone-sensitive lipase

PPAR: Peroxisome proliferator-activated receptor.

\section{Data Availability}

The data used to support the findings of this study are available from the corresponding author upon request.

\section{Conflicts of Interest}

The authors have no conflicts of interest to disclose.

\section{Acknowledgments}

The authors thank Dr. Miguel Arredondo (Laboratory of Micronutrients, Human Nutrition Unit, INTA, University of Chile) for providing the 3T3-L1 cells This work was supported by the Centro de Estudios en Alimentos Procesados (CEAP), CONICYT-Regional, Gore Maule R09I2001, Chile, and Programa de Investigación Asociativa en Cáncer Gástrico (PIA-CG), Universidad de Talca, Chile.

\section{References}

[1] B. Caballero, "The global epidemic of obesity: an overview," Epidemiologic Reviews, vol. 29, no. 1, pp. 1-5, 2007.

[2] M. Ng, T. Fleming, M. Robinson et al., "Global, regional, and national prevalence of overweight and obesity in children and adults during 1980-2013: a systematic analysis for the global burden of disease study," The Lancet, vol. 384, no. 9945, pp. 766-781, 2014. 
[3] I. Bondia-Pons, L. Ryan, and J. A. Martinez, "Oxidative stress and inflammation interactions in human obesity," Journal of Physiology and Biochemistry, vol. 68, no. 4, pp. 701-711, 2012.

[4] A. Everard and P. D. Cani, "Diabetes, obesity and gut microbiota," Best Practice \& Research Clinical Gastroenterology, vol. 27, no. 1, pp. 73-83, 2013.

[5] Q. Q. Tang, T. C. Otto, and M. D. Lane, "Mitotic clonal expansion: a synchronous process required for adipogenesis," Proceedings of the National Academy of Sciences, vol. 100, no. 1, pp. 44-49, 2003.

[6] C. L. Hsu and G. C. Yen, "Phenolic compounds: evidence for inhibitory effects against obesity and their underlying molecular signaling mechanisms," Molecular Nutrition \& Food Research, vol. 52, no. 1, pp. 53-61, 2008.

[7] T. Sun, M. Fu, A. L. Bookout, S. A. Kliewer, and D. J. Mangelsdorf, "MicroRNAlet-7Regulates 3t3-L1 adipogenesis," Molecular Endocrinology, vol. 23, no. 6, pp. 925-931, 2009.

[8] F. M. Gregoire, C. M. Smas, and H. S. Sul, "Understanding adipocyte differentiation," Physiological Reviews, vol. 78, no. 3 , pp. 783-809, 1998.

[9] A. T. Ali, W. E. Hochfeld, R. Myburgh, and M. S. Pepper, "Adipocyte and adipogenesis," European Journal of Cell Biology, vol. 92, no. 6-7, pp. 229-236, 2013.

[10] Y. Song, H. J. Park, S. N. Kang et al., "Blueberry peel extracts inhibit adipogenesis in 3T3-L1 cells and reduce high-fat dietinduced obesity," PLoS One, vol. 8, no. 7, Article ID e69925, 2013.

[11] C. Pheiffer, Z. Dudhia, J. Louw, C. Muller, and E. Joubert, "Cyclopia maculata (honeybush tea) stimulates lipolysis in 3T3-L1 adipocytes," Phytomedicine, vol. 20, no. 13, pp. 1168-1171, 2013.

[12] C. Chavez-Mendoza and E. Sanchez, "Bioactive compounds from Mexican varieties of the common bean (Phaseolus vulgaris): implications for health," Molecules, vol. 22, no. 8, p. $1360,2017$.

[13] B. D. Oomah, A. Corbé, and P. Balasubramanian, "Antioxidant and anti-inflammatory activities of bean (Phaseolus vulgaris L.) hulls," Journal of Agricultural and Food Chemistry, vol. 58, no. 14, pp. 8225-8230, 2010.

[14] P. Maccioni, G. Colombo, A. Riva et al., "Reducing effect of a Phaseolus vulgaris dry extract on operant self-administration of a chocolate-flavoured beverage in rats," British Journal of Nutrition, vol. 104, no. 5, pp. 624-628, 2010.

[15] A. Spadafranca, S. Rinelli, A. Riva et al., "Phaseolus vulgaris extract affects glycometabolic and appetite control in healthy human subjects," British Journal of Nutrition, vol. 109, no. 10, pp. 1789-1795, 2013.

[16] R. Rodríguez-Azúa, E. F. Quinteros, A. Olate-Briones, and R. Moore-Carrasco, "Phaseolus vulgaris exerts an inhibitory effect on platelet aggregation through AKT dependent way," Preventive Nutrition and Food Science, vol. 23, no. 2, pp. 102-107, 2018.

[17] A. M. Hutchins, D. M. Winham, and S. V. Thompson, "Phaseolus beans: impact on glycaemic response and chronic disease risk in human subjects," British Journal of Nutrition, vol. 108, no. 1, pp. S52-S65, 2012.

[18] M. Gupta, P. Sharma, and A. K. Nath, "Purification of a novel $\alpha$-amylase inhibitor from local Himalayan bean (Phaseolus vulgaris) seeds with activity towards bruchid pests and human salivary amylase," Journal of Food Science and Technology, vol. 51, no. 7, pp. 1286-1293, 2014.
[19] C. J. O’Donnell and R. Elosua, "Cardiovascular risk factors. Insights from framingham heart study," Revista Española de Cardiología (English Edition), vol. 61, no. 3, pp. 299-310, 2008.

[20] R. Mariane Lutz, " ¿Podemos hablar de Alimentos funcionales en Chile?," Revista Chilena de Nutrición, vol. 39, no. 2, pp. 211-216, 2012.

[21] R. J. Garrison, M. W. Higgins, and W. B. Kannel, "Obesity and coronary heart disease," Current Opinion in Lipidology, vol. 7, no. 4, pp. 199-202, 1996.

[22] A. H. Berg and P. E. Scherer, "Adipose tissue, inflammation, and cardiovascular disease," Circulation Research, vol. 96, no. 9, pp. 939-949, 2005.

[23] G. R. Hajer, T. W. van Haeften, and F. L. J. Visseren, "Adipose tissue dysfunction in obesity, diabetes, and vascular diseases," European Heart Journal, vol. 29, no. 24, pp. 2959-2971, 2008.

[24] M. Kim, J. E. Park, S. B. Song, and Y. S. Cha, "Effects of black adzuki bean (vigna angularis) extract on proliferation and differentiation of 3T3-L1 preadipocytes into mature adipocytes," Nutrients, vol. 7, no. 1, pp. 277-292, 2015.

[25] B. Stefanon, E. Pomari, and M. Colitti, "Effects of Rosmarinus officinalis extract on human primary omental preadipocytes and adipocytes," Experimental Biology and Medicine, vol. 240, no. 7, pp. 884-895, 2015.

[26] R. Campos-Vega, G. Loarca-Piña, and B. D. Oomah, "Minor components of pulses and their potential impact on human health," Food Research International, vol. 43, no. 2, pp. 461-482, 2010.

[27] S. Smulikowska, B. Pastuszewska, E. Święch et al., "Tannin content affects negatively nutritive value of pea for monogastrics," Journal of Animal and Feed Sciences, vol. 10, no. 3, pp. 511-523, 2001.

[28] N. Fantini, C. Cabras, C. Lobina et al., "Reducing effect of a Phaseolus vulgaris dry extract on food intake, body weight, and glycemia in rats," Journal of Agricultural and Food Chemistry, vol. 57, no. 19, pp. 9316-9323, 2009.

[29] M. A. M. Carai, N. Fantini, B. Loi et al., "Multiple cycles of repeated treatments with a Phaseolus vulgaris dry extract reduce food intake and body weight in obese rats," British Journal of Nutrition, vol. 106, no. 5, pp. 762-108, 2011.

[30] A. K. Ramírez-Jiménez, R. Reynoso-Camacho, M. E. Tejero, F. León-Galván, and G. Loarca-Piña, "Potential role of bioactive compounds of Phaseolus vulgaris L. on lipid-lowering mechanisms," Food Research International, vol. 76, pp. 92104, 2015.

[31] L. Celleno, M. V. Tolaini, A. D’Amore, N. V. Perricone, and H. G. Preuss, "A Dietary supplement containing standardized Phaseolus vulgaris extract influences body composition of overweight men and women," International Journal of Medical Sciences, vol. 4, no. 1, pp. 45-52, 2007.

[32] T. Kitano-Okada, A. Ito, A. Koide et al., "Anti-obesity role of adzuki bean extract containing polyphenols: in vivo and in vitro effects," Journal of the Science of Food and Agriculture, vol. 92, no. 13, pp. 2644-2651, 2012.

[33] H. Lee, Y. J. Lee, H. Choi, E. H. Ko, and J. W. Kim, "Reactive oxygen species facilitate adipocyte differentiation by accelerating mitotic clonal expansion," Journal of Biological Chemistry, vol. 284, no. 16, pp. 10601-10609, 2009.

[34] Q. Wang, S. T. Wang, X. Yang, P. P. You, and W. Zhang, "Myricetin suppresses differentiation of 3T3-L1 preadipocytes and enhances lipolysis in adipocytes," Nutrition Research, vol. 35, no. 4, pp. 317-327, 2015. 


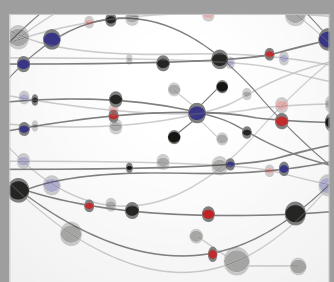

The Scientific World Journal
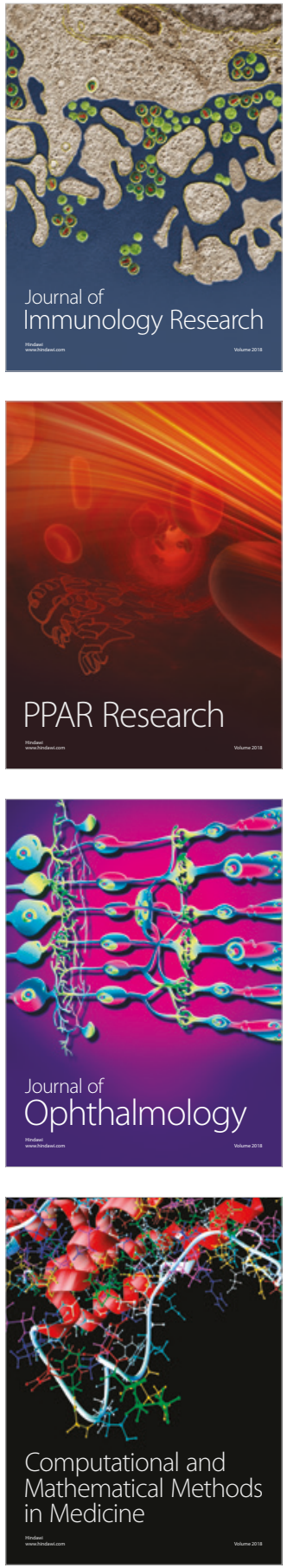

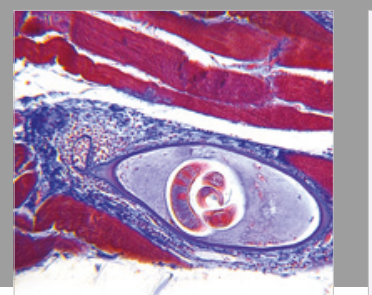

Gastroenterology Research and Practice

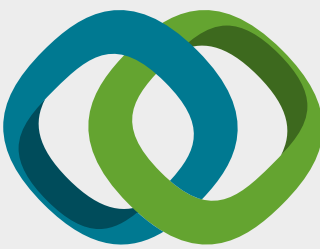

\section{Hindawi}

Submit your manuscripts at

www.hindawi.com
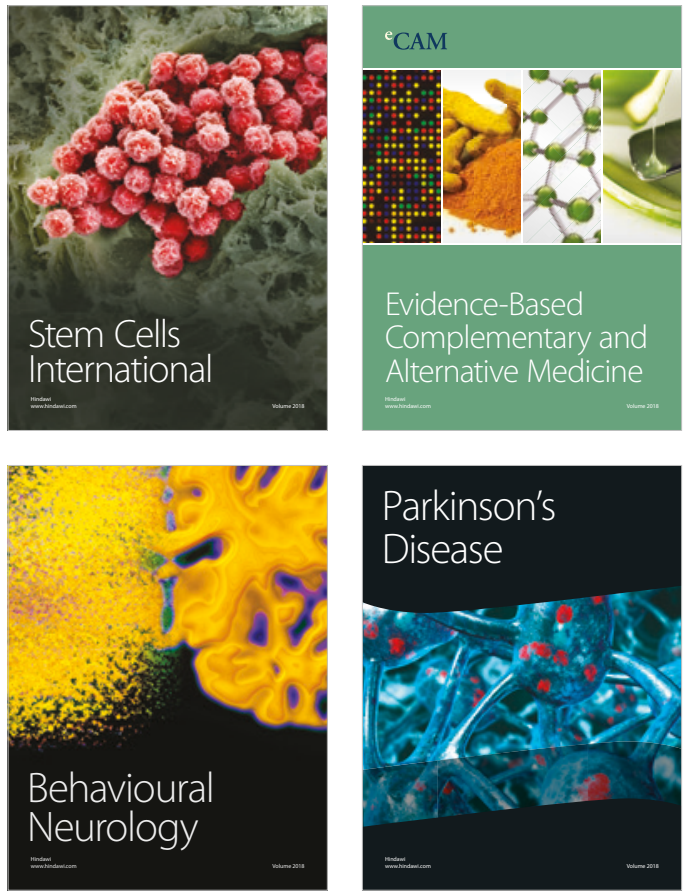

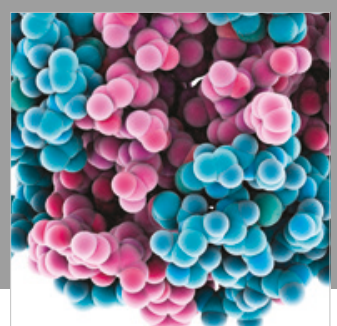

ournal of

Diabetes Research

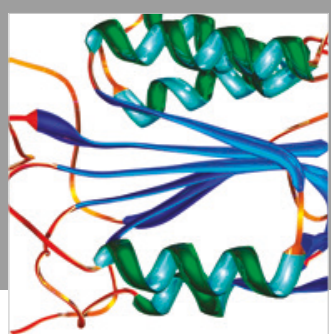

Disease Markers
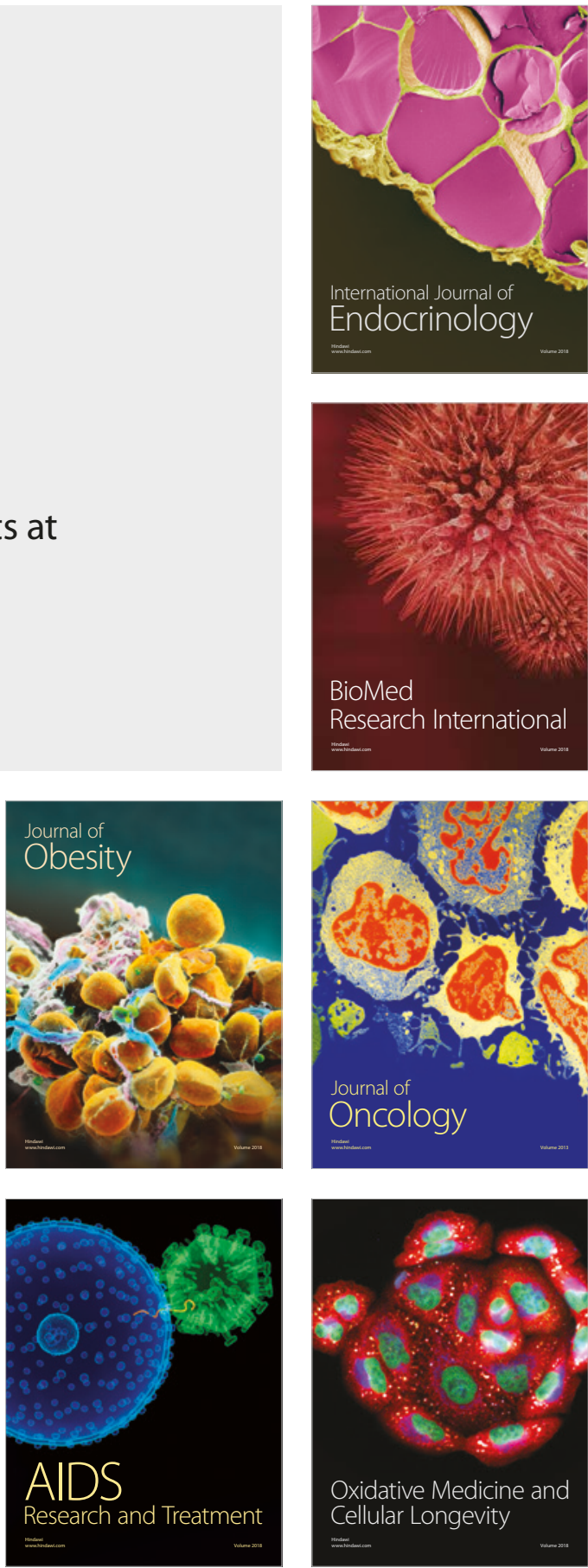